\title{
EVOLUÇÃO HISTÓRICA E DESAFIOS DOS MODELOS DE ESTADO DE DIREITO
}

\section{HISTORICAL EVOLUTION AND CHALLENGES OF THE RULE OF LAW MODELS}

${ }^{1}$ Rodrigo Lima e Silva

\begin{abstract}
RESUMO
O presente artigo pretende apresentar o desenvolvimento do conceito Estado de Direito, apontando sua origem bem como a evolução do modelo inicial até os dias atuais em nível mundial, analisando como o fenômeno ocorreu diante das peculiaridades brasileiras, onde o atual modelo de Estado democrático de direito é tido sob a perspectiva de garantir o respeito das liberdades civis, dos direitos humanos e das garantias fundamentais, inobstante a falta generalizada de inclusão no sistema jurídico. A compreensão de tais transformações é importante para um melhor conhecimento das dinâmicas estatais em países que sofrem com uma base democrática vulnerável e com o crônico desrespeito às garantias e liberdades individuais.
\end{abstract}

Palavras-chave: Estado de direito, Origem, Transformação

\begin{abstract}
This article aims to present the development of the concept rule of law, indicating its origin and evolution of the original model to the present day worldwide, analyzing how the phenomenon occurred before the Brazilian peculiarities, where the current democratic state model of law is taken from the perspective of ensuring respect for civil liberties, human rights and fundamental guarantees, despite the general lack of inclusion in the legal system. The comprehension of these transformationis important for a better understanding of the state dynamics in countries that suffers from a vulnerable democratic basis and with chronic disregard for guarantees and individual freedoms.
\end{abstract}

Keywords:Rule of law, Origin, Transformation

${ }^{1}$ Doutorando em Ciência Política pela Universidade Federal Rural do Rio de Janeiro, UFRRJ - RJ, (Brasil). Atualmente é professor na área de direito público da Universidade Federal Rural do Rio de Janeiro, UFRRJ - RJ, (Brasil).E-mail:rodivo@terra.com.br 


\section{1-INTRODUÇÃO:}

O ideário que deu fundamento à construção de uma teoria do Estado remonta a tempos longínquosi, todavia, a origem do conceito de Estado de Direitoii surgiu já na Idade Moderna, no âmbito do Estado Moderno, criado em oposição ao Estado absolutista, seja em sua versão de força, autoritária (Machstsst, Estado de força), seja em sua versão mais ilustrada (Polizeistaat, Estado de polícia, como é denominado pela teoria alemã).

Existe uma diferença teórica entre o conceito de Estado de Direito, oriundo de uma expressão europeia-continental "Estado de Direito" (Rechstaat, État de droit. Stato di diritto, Estado de derecho) e o chamado rule of law, típico da cultura anglo-saxônica.

Universalmente difundidas, as duas fórmulas remetem a tradições políticas e jurídicas distintas.

A primeira radica na cultura liberal alemã da segunda metade do século XIX que, em seguida, difundiu-se no continente, influenciando o direito público da Itália unitária e da Terceira República francesa, ao passo que a segunda tem posição destacada na história política e constitucional da Grã-Bretanha, desde a conquista normanda até a Era Moderna, tendo como marca na Constituição norte americana e de muitos outros países que sofreram a influência das instituições britânicas (ZOLO, 2006, p.4).

A expressão "Estado de Direito" é utilizada comumente sem respeitar seu duplo sentido, tendo em vista possuir duas conotações; uma primeira conotação, ampla, fraca ou formal, e outra conotação em sentido forte ou substancial.

Conforme Zolo (2006) em relação à primeira hipótese, "Estado de Direito" designa qualquer ordenamento no qual "os poderes públicos são conferidos pela lei e exercidos nas formas e com os procedimentos por ela estabelecidos (ZOLO, 2006, p. 417)”.

Em sentido forte ou substancial, a definição do Estado de Direito remete àqueles ordenamentos nos quais os poderes públicos estão igualmente sujeitos à lei, não apenas quanto às formas, mas também quanto aos conteúdos de seu exercício.

Num sentido mais restrito, são "Estados de Direito" "aqueles ordenamentos nos quais todos os poderes, inclusive o Legislativo, estão vinculados ao respeito de princípios substanciais, estabelecidos costumeiramente por normas constitucionais" (ZOLO, 2006, p. 417), como a separação dos poderes e os direitos fundamentais.

Bobbio (2007), por sua vez, afirma que a evolução do conceito de Estado de Direito poderia ser descrita como: 
“(...) processo de desmonopolização do poder ideológico de um lado, e de desmonopolização do poder econômico do outro. Ao Estado resta, e restará até quando for um Estado, o monopólio da força através do qual deve ser assegurada a livre circulação de ideias (e portanto o fim de toda ortodoxia) e a livre circulação dos bens (e portanto o fim de toda forma de protecionismo)."(BOBBIO, 2007, p. 125)

A evolução, segundo Bobbio (2007), não é linear, pois a noção de "Estado de Direito" retorna ao Ocidente em estreita ligação com a doutrina dos direitos subjetivos (ou "direitos fundamentais").

Essa noção emerge como teoria político-jurídica que põe em primeiro plano a tutela dos direitos do homem, definidos por uma longa série de constituições nacionais e convenções internacionais no decorrer dos séculos XIX e XX, em particular, reconhecendo o direito à vida e à segurança pessoal, à liberdade, à propriedade privada, autonomia de negociação e aos direitos políticos.

Lênio Streck (2003, p. 86-87) observa que o conceito de "Estado de Direito", surge na segunda metade do século XVIII, “com o objetivo de enquadrar e limitar o poder do Estado pelo Direito" e com a noção da prescrição da supremacia da lei sobre a administração.

Delimitar essas compreensões, apresentar os principais marcos teóricos sobre o assunto e contribuir para um melhor estudo de base histórica e teórica para a concepção dos modelos de Estados de Direito é o principal objetivo desse artigo, como se demonstrará nos próximos tópicos.

Sobre a importância do objeto de estudo, denota-se que a compreensão dessas dinâmicas possui uma grande relevância pois como salienta Canotilho (1991) a história do Estado de Direito não deve ser compreendida como a história de um conceito, mas como algo que faz parte da "história geral das ideias e das instituições"( CANOTILHO, 1991, p. 353).

\section{2 - DO ESTADO DE DIREITO LIBERAL}

A ideia de um Estado de Direito se relacionou em grande medida à ascensão da burguesia como classe, ao incremento de uma teoria dos direitos humanos e à quebra da unidade ideológica com a Igreja.

Dessa forma, de início, o "Estado de Direito" identificou-se com a consolidação liberal dos ideais burgueses do final do século XVIII, institucionalizados e levados a efeito no modelo do Estado liberal, caracterizado para dar conta da realização de tais pretensões como 
"Estado de Direito", isto é, pautado e vinculado à figura da lei, que constitui os limites e o fundamento necessário de todas as suas ações iii.

Nesse modelo de Estado, além de os indivíduos estarem sujeitos à ordem jurídica, também são impostos limites e mecanismos de controle ao exercício do poder do Estado, seja através de direitos individuais garantidos constitucionalmente, seja através de instituições jurídicas encarregadas de defender e proteger tais direitos frente ao Estado iv.

Não é por outra razão que Danilo Zolo e Piero Costa (2006) afirmam que o Estado de Direito instaura o "nexo funcional entre o poder e os sujeitos".

O paradigma de Estado de Direito tem como espaço geográfico de influência a França, onde inicialmente, se passou do feudalismo para a Idade Moderna, operando-se, com base na figura do príncipe (monarca), um fenômeno de personalização e de centralização territorial de poder, em substituição ao modelo policêntrico e descentralizado, que identificava o período medieval.

Nessa estrutura, o monarca confundia-se com o próprio Estado, concentrando as prerrogativas e poderes necessários à consolidação da unidade interna.

Com tal estrutura e formação, o acesso ao poder político era intensamente dificultado no que se refere a burguesia (uma classe mercantil ascendente de poderio econômico) que se posicionava contrariamente aos interesses da nobreza e do clero.

Surgiram, então as principais revoluções burguesas, com destaque à Revolução Francesa de 1789 v.

A Declaração dos Direitos do Homem e do Cidadão foi o atestado de óbito do Antigo Regime, destruído pela Revolução, onde houve a proclamação da liberdade, da igualdade e da soberania popular.

Assim, tal modelo de Estado centralizava a produção de normas nas mãos da burguesia e com a divisão de poderes, foram necessárias novas técnicas de proteção aos direitos da liberdade. Entretanto, essas técnicas eram apenas fórmulas para garantir a realização de pretensões materiais pretendidas pela própria burguesiavi. Como bem anota Canotilho:

"mais do que um conceito jurídico, o Estado de direito era um conceito político e, além disso, um conceito de luta política. Concretamente, constituía o instrumento da luta política da burguesia contra o Estado absolutista centralizador, contra os resquícios do Estado feudal, contra as sobrevivências estamentais"(CANOTILHO, 1991, p. 356)

$\mathrm{Na}$ base desses movimentos burgueses, estava a pretensão de igualdade jurídica e também a garantia de exercício irrestrito das liberdades individuais, tidas como inerentes e inatas a cada indivíduo, em razão de sua simples condição, reforçadas pelo surgimento da noção de 
direitos naturais, na esteira do pensamento de John Lockevii, para quem esses direitos (notadamente, direito à vida, à liberdade e à propriedade), exatamente por serem inatos, são anteriores ao Estado e, por conseguinte, devem ser respeitados.viii

Foi dessa forma que, em reação aos ordenamentos medievais e absolutistas, à sua pluralidade de poderes concorrentes e à oposição histórica e secular entre a liberdade do indivíduo e o absolutismo do monarca, estruturou-se o Estado liberal de Direito, no qual se refletiu a pugna da liberdade e da propriedade contra o despotismona área continental europeia ix.

Concorrentemente a este movimento, surgia a ideia de contrato social (atribuída a Rousseau) que justifica o surgimento e a existência do Estado (e consequentemente o próprio poder). Esse contrato social, em apertada síntese, resultaria em um acordo celebrado por homens livres e iguais, que delegam a função de assegurar suas liberdades e os seus direitos ao Estado.

Logo, o indivíduo entregaria uma parcela de seus direitos ao Estado, que assume a missão de garanti-los, estabelecendo-se regras genéricas aplicáveis a todos indistintamente, bem como regras mínimas de condutas baseadas em direitos e deveres recíprocos, ou seja, quando todos cumprissem seus deveres, os direitos individuais de todos os outros estariam protegidos.

Dessa forma, o Estado somente poderia intervir o mínimo possível, estabelecendo-se a máxima liberdade individual, principalmente na esfera privada.

Surgindo então a ideia de que o Estado deve estar a serviço do homem e não o contrário, o que permite que se imponham limites às suas atividades e ao seu poder.

Com base nesses ideais, reforçou-se a concepção liberal ou individualista de cidadania, restrita à proteção dos direitos dos indivíduos, sem qualquer interferência do poder estatal na vida privada.

Entretanto, a burguesia não seguiu em obediência aos princípios filosóficos que sustentaram sua revolta social (diga-se de passagem, devido à manutenção egoística de seus interesses), concluiu-se que o Estado jurídico puro fora insuficiente por não ter sucesso no que se refere à alteração das realidades sociais, tendo em vista sua inércia diante das mais variadas situações e por não corresponder satisfatoriamente às necessidades demandadas pela vida em sociedade, dando oportunidade para o surgimento da ideia de que a igualdade em que se sustentou o liberalismo era apenas formal e não substancial e que a liberdade tão desejada se identificava com a emancipação econômica.

Nesse momento, transformou-se o ideário de cidadania, que passou do plano civil e político para a esfera social, conferindo-se à ordem jurídica o papel de atuar também para o alcance de metas sociais concretas, dentro de uma lógica distributiva de satisfação e direitos 
humanos sociais, igualitários, destinados a organizar a sociedade segundo o ideal de justiça e bem-estar para todos.

A necessidade de uma mudança no perfil do Estado de direito liberal para atender à essas novas demandas se tornou premente, dando origem ao estado do bem estar social.

\section{3 - DO ESTADO DO BEM-ESTAR SOCIAL (WELFAR ESTATE)}

O papel atribuído formalmente ao Estado de Direito deixou, assim, de ser neutro e individualista, para transformar-se em Estado Material de Direito, com a pretensão de realização da justiça social.

Diante de tal cenário, o Estado de Bem Estar social (Welfare State, como é chamado) encontra terreno fértil para se desenvolver, estimulando novos interesses e novas demandas devido ao aumento desordenado das classes operárias em razão da Revolução Industrial e da expansão territorial que trouxeram à tona as mazelas da intensa desigualdade social.

A exigência da sociedade de novas atuações por parte do Estado para concretizar o princípio da igualdade, em substituição à mera igualdade formal, típica do liberalismo, exigiu uma maior atuação estatal para mitigar as desigualdades.

Essa transformação ocorreu sob a égide da lei, que recebe uma posição política destacada, não ocorrendo um abandono ao pensamento inicial de Estado de Direito, mas apenas dando-lhe uma nova roupagem como forma de atender às demandas e necessidades sociais.

Por conta disso, Dallari (1989, p. 233) elencou o que entende serem as causas privilegiadas deste processo de transformação do perfil mínimo adotado pelo Estado Liberal, nos seguintes termos:

A - A Revolução Industrial e suas consequências de proletarização, urbanização (transporte, saúde, saneamento, moradia), mudança nas condições de trabalho, previdência e degradação ambiental.

B - A primeira guerra mundial rompe a tradição do liberalismo econômico, acelerando violentamente a ação de fatores desagregadores. De fato, tal guerra dilata as exigências de armamento e aprovisionamento, demonstrando a necessidade de controle integral e coativo da vida econômica, também como reflexo da emergência da Revolução Russa, da Constituição de Weimar de 1919 e do constitucionalismo social, iniciado pela Constituição mexicana de 1917.

C - A crise econômica de 1929 e a Depressão trouxeram embutida a necessidade de uma economia interventiva, de maneira a reconciliar os dois maiores fatores de estabilidade 
econômica: a iniciativa privada e a ação governamental, que engendram a política social de Roosevelt e o New Deal americanos, uma intensa política de nacionalizações implementada por Atlee, após a II Guerra Mundial, bem como os reflexos da ação de Leon Blum e a Front Populaire, no caso francês.

D - A Segunda Guerra Mundial, com a emergência de conflito que impôs a assunção de um papel controlador dos recursos sociais, bem como de uma atitude prática por parte do ente estatal, com o objetivo de manter a produção, a distribuição, o controle da economia e similares, sem que se restrinja a uma atitude reconhecedora e repressora.

E - As crises cíclicas as quais, já no final do século, apontavam para as fissuras do liberalismo, em seu viés econômico e afetavam o comportamento da economia, sendo que a ação nefasta dos monopólios e o aumento das desigualdades sociais comprometiam a subsistência do regime.

F - Os movimentos sociais rechaçam o dogma de que a livre força do mercado, supostamente regulado por mão invisível, seria capaz de levar a bom termo o processo econômico. O interesse social, muitas vezes, revelou-se incompatível com a livre concorrência.

G - Há uma liberdade positiva em lugar de potencialidade (não garantida) liberal, sustentada em suas liberdades negativas - de não-impedimento, o que implica a mudança de sentido das liberdades liberais, pela incorporação das liberdades sociais ou liberdades positivas.

No campo político, a Europa convivia com o nazi-fascismo, a URSS com o socialismo real e a independência dos países afro-asiáticos que deixaram a mostra o subdesenvolvimento, que passou a exigir a intervenção do Estadox.

Diante das tensões sociais e do intervencionismo estatal, a burguesia sentiu-se ameaçada, o que propiciou maior flexibilização do regime liberal.

Da mesma forma, a burguesia também se beneficiou da ação do Estado, que aplicou verbas públicas constituídas pela poupança e taxação generalizada na implementação da infraestrutura necessária ao desenvolvimento das atividades de acumulação e expansão de capital (SCAFF, 1990).

Realizar a concepção do Estado do Bem-estar social também se tornou difícil diante de demandas sociais cada vez maiores que impulsionaram o Estado para um novo aprimoramento: O Estado Democrático de Direito. 


\section{4 - DO ESTADO DEMOCRÁTICO DE DIREITO E O PARADIGMA DO CONSTITUCIONALISMO}

Com o advento do Estado Democrático de Direito, o que se busca é a conjugação da noção de Estado de Direito ao ideal democrático, com o intuito de manter as conquistas obtidas até então, agregando-lhe novas xi.

Sem negar os objetivos do modelo do Estado de Bem-Estar, mas, por outro lado, insistindo na íntima e necessária conexão entre os princípios democrático e social, este Estado democrático de direito surge com a intenção constitucional de realização do Estado Social, por isso, considerado um plus normativo em relação ao modelo promotor intervencionista daquela acepção de Estado xii.

Contudo, como adverte Streck (2002), este plus normativo não depende de maior produção legislativa, mas requer a mudança de enfoque dos fins almejados pelas normas que, revestidas do caráter democrático, buscam uma constante reestruturação das relações sociais, com a real concretização do princípio da igualdade.

Barroso (2006 )xiii informa que o marco histórico desse movimento constitucional, na Europa continental, foi o constitucionalismo do pós-guerra, especialmente na Alemanha e na Itália e, no Brasil, foi a Constituição da República de 1988 sendo que o marco teórico que indica o processo de redemocratização é dividido em três momentos: a) o reconhecimento de força normativa da Constituição; b) a expansão da jurisdição constitucional; c) o desenvolvimento de nova perspectiva da interpretação constitucional.

Desde então, o Estado Democrático de Direito ou Estado Constitucional de Direito, apresenta nova configuração do princípio da legalidade, a partir do qual, para além da definição inicial de submissão do Poder Público à lei - presente nos modelos liberal e social - tem-se a submissão de todo o poder do Estado ao Direito e mais do que isso, um Estado submetido à uma Constituição primordialmente.

Em decorrência disso, é necessária uma Constituição robusta, com status de referencial hermenêutico, capacidade de concretizar utopias (STRECK, 2002) e, ligada a uma substancial democracia com a potencialidade de promoção de direitos sociais de um lado e, de outro, de controle dos atos de Poder emanados do Estado, (des) legitimandoos, estabelecendo um rol de garantias individuais e um núcleo de proteção a essas garantias, assegurando-as, como pretenderse-á demonstrar.

Por conta disso, fica estabelecida uma correlação com o que se chama de princípio da constitucionalidade, explica-se: em decorrência da robustez constitucional, a Lei Maior é 
portadora de normatividade e ocupa espaço hierarquicamente superior no ordenamento jurídico em relação às demais normas.

É assim que, no Estado Democrático de Direito, a Constituição assume caráter vinculante e indisponível aos poderes exercidos pelo Estado, consolidando seus fins sociais, as garantias e os direitos fundamentais dos cidadãos xiv.

Trata-se, pois, de "uma forma privilegiada de instrumentalizar a ação do Estado na busca do desiderato apontado pelo texto constitucional, entendido no seu todo dirigente-valorativoprincipiológico"(STRECK, 2002, p. 128).

Ao lado de tal rigidez constitucional, a busca de um Estado Social e Democrático, pretende alcançar através da organização democrática da sociedade (onde ao princípio do Estado de Direito será agregado o ideal democrático), a consolidação da garantia e segurança de um sistema de direitos fundamentais individuais e coletivos, utilizando-se de instrumentos e políticas públicas orientadas para diminuir desigualdades e conseguir a Justiça Social xv.

A partir dessa ideia, a Constituição, garante um núcleo de direitos e garantias fundamentais aos cidadãos e indisponíveis aos que exercem o poder, cujo exercício é legitimado pela democracia.

Nessa linha de pensamento, assumem relevância, tanto a democracia formal, quanto a substancial xvi.

A democracia formal trata dos elementos formais, analisando-se o conjunto de normas e instituições que conformam os procedimentos e organizam as estruturas estatais. Nesse passo, a título exemplificativo, pode-se mencionar: o princípio da representação, princípio da participação, as normas sobre sufrágio universal, o princípio da maioria na formação das decisões, os diversos métodos de eleição indiretade diferentes órgãos do Estado.

Ferrajoli (2002), afirma que as condições formais de validade são as regras sobre "quem" pode e "como" se deve decidir, as formas de expressão da soberania popular, estabelecendo competências e procedimentos, cuja inobservância é causa de inexistência ou falta de vigência das normas.

É, pois, a democracia formal, da qual é extraída o caráter politicamente democrático do sistema político no Estado de Direito.

Por outro lado, a democracia substancial acaba tendo a função de fortalecer e legitimar o Estado de Direito democrático. De la Cueva (1996, p. 112), aponta que as dimensões substancial (material) e formal são inseparáveis. Tendo em vista, a democracia como forma (derechos del ciudadano, y especificamente, la universalidad del derecho activo y pasivo de voto em relacion com todos los asuntos y para todos los cargos publico) ser o caminho necessário e único para 
conquistar a democracia material - substancial - (los derechos del hombre, y concretamente, la igualdad y la libertad civile).

Ressalte-se que a democracia será substancial quando intentar proteger os direitos fundamentais, que se apresentam como garantia jurídica, previstos na Constituição. As condições substanciais fazem referência à estrutura do poder; ou seja, regras sobre o que se deve ou não se deve decidir.

Definindo-se as regras de Estado de Direito - partindo desse pressuposto substancial de validade - são as que garantem os direitos fundamentais dos cidadãos, estabelecendo o que "não se deve" ou "o que se deve" decidir e impondo proibições e obrigações aos poderes do Estado.

Assim, um Estado constitucional de direito desenvolve-se a partir do término da 2. auerra e se aprofunda no último quarto do século XX, tendo por característica central a subordinação da legalidade a uma Constituição rígida.

A validade das leis já não depende apenas da forma de sua produção, mas também da compatibilidade de seu conteúdo com as normas constitucionais e, mais que isso, a Constituição não apenas impõe limites ao legislador e ao administrador, mas lhes determina também deveres de atuação.

A ciência do direito também assume um papel crítico e indutivo da atuação dos Poderes Públicos e a jurisprudência passa a ter nova importância, incluindo dentre outras funções, a competência ampla para invalidar atos legislativos ou administrativos e para interpretar as normas jurídicas à luz da Constituição.

\section{5 - O ESTADO DE DIREITO NO BRASIL E A FALTA DE INCLUSÃO NO SISTEMA JURÍDICO.}

Em relação aos países da América Latina o processo transcorreu de maneira diferente.

Em decorrência de seu histórico que envolve processo de colonização, séculos de governos autoritários, industrialização tardia e dependência periférica, não foi possível assegurar a efetividade de um Estado de Bem-Estar Social, pois ointervencionismo nesses países se vestia de autoritarismo e ditaduras, sendo o contrário de um Estado Providência, o que aumentou o processo de empobrecimento das populações e as diferenças sociais e assim, a tese intervencionista sempre esteve ligada ao patrimonialismo das elites herdeiras do colonialismo (STRECK, 2003). 
Entretanto, a crise do Estado Social também trouxe consigo a crise do Direito e cada modelo de Estado traz consigo um modelo de Direito que dá fundamento às suas políticas e isso não seria diferente no Welfare State.

Informa Campilongo (1997), que o esgotamento das potencialidades do Direito nos Estados intervencionistas, ocorreu "pela impotência da pretensão totalizante do direito estatal e pelo exaurimento das virtudes do processo reformador, planejador e redistribuidor de recursos a que se propunha".

Diante do impasse, surge a necessidade de uma releitura do paradigma anterior, com a intenção de repensar seus fundamentos, como sugere Marinho (2000, p. 89).

Tendo como perspectiva tal cenário, o surgimento de uma concepção democrática do Estado de Direito nos países de modernidade tardia indicava a resposta às imprecisões e insuficiências do Estado Social, tendo-se em mente que o "Estado Providência" não deu conta de todos os papéis que lhe foram atribuídosxvii, em razão da falta de estrutura socioeconômica, que pudesse efetivar os direitos sociais exigidos, que impossibilitava o equilíbrio entre a justiça social e a participação democrática dos cidadãos no processo político.

Não se pode esquecer que o Brasil República sofreu forte influência constitucional norte-americana - a começar pelo novo nome político que lhe atribuiu Rui Barbosa: Estados Unidos do Brasil. Por exemplo, a Constituição de 1891 fortaleceu o judiciário e o apresentou como um dos três poderes "harmônicos e independentes entre si", disposição que foi mantida pelas Constituições posteriores, exceto a de 1937 xviii.

Entretanto, essa influência, era duplamente artificial: "nem tínhamos realeza e nobreza para acomodar institucionalmente, posto terem sido aposentadas pela República”; nem tínhamos que "lidar com autonomias estaduais, já que as antigas Províncias faziam parte de um Império unitário” (MACHADO, 1994, p. 85).

Além disso, a expressão "poderes independentes" permite interpretação abusiva da teoria que originou a fórmula importada, "pois o que se busca com a separação dos poderes é a sua limitação mútua, enquanto que o que se obtém com a sua independência é uma lógica de expansão isolacionista, e com o isolamento podem vir a irresponsabilidade, o privilégio e o abuso" (MACHADO, 1994).

Assim, cumpre retornar ao período da ditadura do Governo Provisório, quando se inaugurou o ideário do Estado Social no Brasil, aplicado precipuamente às relações trabalhistas.

Após o interregno da Constituição de 1934, instituiu-se o Estado Novo, sob poder de Getúlio Vargas, a estatalidade social sustentou a ditadura e manteve um regime de supressão das 
garantias constitucionais e de aniquilamento das liberdades públicas, o que representava antítese do Estado de Direito.

Finalmente, por meio de nova ditadura, instalou-se outra fase do autoritarismo republicano.

Com maior duração e tão rígida quanto a do Estado Novo, pretendeu-se conferir legitimidade, por meio de um Ato Institucional, às partes remanescentes da Constituição de 1946, que fora obra de constituintes do povo, cujos fundamentos foram aniquilados pelo golpe de Estado de 1964.

Posteriormente, em 1967, um Congresso sem legitimidade popular para o exercício da função constituinte com seus quadros representativos abalados pelas cassações revolucionárias, elaborou nova Constituição, gerando uma crise constitucional que acabou por se agravar com a Emenda n. ${ }^{\circ}$, em 1969, quando o triunvirato militar, usurpando o poder, transformou a Constituição em Ato Institucional, composto de 200 artigos.

Durante esse período, verifica-se a implosão do edifício constitucional da sociedade brasileira, formalizado no Estado de Direito, de cunho formalista e contextura clássica, herança de três constituições republicanas, e também, pouco se fez para dar continuidade à obra de construção do Estado social emergente.

Após esse momento, a ditadura perde suas forças com a revogação do AI- 5, a Lei de Anistia xix, a implementação de eleições diretas para governador xx e revitalização da liberdade de imprensa xxi.

De fato, como explica Bonavides (1984), as ditaduras republicanas do século XX foram manifestamente anti-federativas, centralizadoras e unitaristas. A primeira "procrastinou a reconstitucionalização e feriu as autonomias"; a segunda "incinerou as bandeiras dos Estadosmembros" e a terceira transformou o governo de cada Estado "numa interventoria federal, com o processo de eleição indireta".

Até que em 1988, o Brasil celebrou a promulgação da Constituição da República, sob pressão dos movimentos sociais organizados que buscavam a criação de Estado com nova roupagem, o Estado Democrático de Direito.

Nesse processo, foram redimensionadas as funções atribuídas aos poderes públicos, o que, sem dúvida, atingiu a tradicional definição das zonas de tolerância de um poder em relação às decisões dos demais.

Essa transformação tem relevo prático e teórico, uma vez que o Poder Judiciário passa a assumir a atribuição de concretizar a Carta Constitucional, que abriga uma série de direitos sociais, coletivos, difusos e transindividuais, cuja realização pode alterar uma realidade 
social injusta e cruel, em decorrência do abismo social, oriundo das diferenças criadas pela defeituosa distribuição de riquezas.

Nesse movimento de evolução estatal, também se verificaram alterações nos princípios constitucionais que garantem direitos individuais e coletivos, o que alcança igualmente o processo penal.

Logicamente, essa evolução requer releitura de quase a totalidade de um conjunto de leis existentes à época da promulgação da constituição de 1988, cuja hermenêutica demanda adequação à Lei Maior, em razão dos contextos em que surgiram, por isso há atualmente uma celeuma para as mudanças dos Códigos de Processo Civil e de Processo Penal.

Em paralelo, a análise da transformação do paradigma do Estado de Direito em outros espaços geográficos, é importante para apontar como isso ocorreu no tempo.

A concretização do Estado de Democrático de Direito no Brasil é complicada, devido à generalização das relações de sub-integração e de sobre-integração, como aponta Marcelo Neves (2006, p. 248).

A partir dessas definições, o autor analisa o que designa como "falta generalizada de inclusão no sistema jurídico", no sentido de ausência de direitos e deveres partilhados reciprocamente: do lado dos sub-integrados, generalizam-se situações em que não têm acesso aos benefícios do ordenamento jurídico estatal, mas dependem de suas prescrições impositivas, ficando os sub-cidadãos excluídos, pois embora lhes faltem as condições reais de exercer os direitos fundamentais constitucionalmente declarados, não estão liberados dos deveres e responsabilidades impostas pelo aparelho coercitivo estatal.

Eles se submetem radicalmente às estruturas punitivas; em síntese, para os subintegrados, os dispositivos constitucionais têm relevância quase exclusivamente em seus efeitos restritivos de liberdade xxii.

No campo constitucional, o problema da sub-integração detém relevância, na medida em que com relação aos membros das camadas subalternas, as ofensas aos direitos fundamentais são praticadas principalmente no âmbito da atividade repressiva do "aparelho estatal"; ou seja, das ações violentas ilegais da polícia e a incidência desenfreada de um populismo punitivo, que por outro lado, estimula a atividade de um código de processo penal divorciado das garantias previstas na Constituição Federal.

Por sua vez, a sobre-integração refere-se a grupos privilegiados que, com o apoio da burocracia estatal, desenvolvem atividades bloqueadoras da disseminação e universalização do direito. 
Os sobre-integrados, são titulares de direitos, competências, poderes e prerrogativas, mas não se subordinam regularmente à atividade punitiva do Estado, no que se refere aos seus direitos e responsabilidades, possuem uma relação instrumental com a ordem jurídica: usam, desusam ou abusam-na conforme as constelações concretas e particularistas de seus interesses. Nesse cenário, o Direito se apresenta como meio de alcance de seus objetivos econômicos, políticos e relacionais.

Sob essa perspectiva de análise, haveria duas modalidades de "excluídos" da ordem jurídica: os sub-integrados e os sobre-integrados, aquele estaria "abaixo do direito" e este último "acima do direito".

Nesse diapasão, as práticas estatais devem ter como bússola a proteção do núcleo de direitos fundamentais, invioláveis, sendo o Estado atingido de morte, quando esses direitos são violados.

Se a idéia de um Estado Democrático de Direito está vinculada à de submissão do Poder à Constituição, este Estado é ferido, quando o Poder deixa de respeitar a norma suprema, agindo ao arrepio dos conteúdos por ela proclamados e da finalidade constitucional, principalmente quando se afasta de um de seus pilares que é a igualdade, como se dá em relação ao tratamento daqueles que se encontram não inseridos no sistema.

\section{6 - CONCLUSÃO}

O conceito de Estado de Direito evoluiu passando por transformações de acordo com as exigências sociais de cada época.

No entanto, deve ficar claro que o Estado de Direito não significa finalidade e conteúdo do Estado, senão o modo e o caráter de sua realização.

Assim, o Estado de Direito pode ser reconhecido como sendo o instrumento e a forma pela qual se reveste a consecução de seus fins - que podem ser tanto de manutenção do status quo vigente, como é o caso do Estado burguês, liberal, ou de transformação de ordem vigente, como é o caso do Estado Democrático de Direito.

Como ficou apontado no texto desenvolvido, tempos atrás, a insatisfação de uma classe (burguesia) contra o absolutismo exigiu posteriormente, que esse Estado submisso às leis pudesse atender às demandas sociais cada vez maiores.

Com o surgimento do modelo que sucedeu o Estado Liberal, o Estado de Bem Estar social (Welfare State, como é chamado) não abandonou o seu primado, mas assimilou novos ideais de conformação e novos interesses, principalmente de parte das classes operárias, cuja 
explosão se identificou com a Revolução Industrial, sendo isso devido também à expansão dos núcleos urbanos, que acresceu ao cenário uma intensa desigualdade social.

Neste momento os indivíduos em sociedade iniciaram a exigência de novas atuações por parte do Estado, intentando uma pretensão material de igualdade, em substituição à mera igualdade formal, típica do liberalismo.

Tratou-se de uma tentativa de se conferir ao Estado de Direito uma conotação de conteúdo mais econômico e social, sem contudo, renunciar à sua forma, que somente deveria assimilar novas realidades e serem operacionalizadas, agora, no sentido de uma democracia social.

Logo a intenção foi de mudança do conteúdo que se reveste o Estado, passando a exigir por parte do Estado uma atuação para garantir direitos sociais mínimos, como educação, saúde e trabalho, por exemplo.

Dessa forma o Estado passou a possuir uma posição mais interventiva e atuante que não encontra mais na figura da lei exclusivamente limites para a sua atuação (existem outros limites como o Direito e a Constituição), mas também imposições de atuação e realização, havendo um fenômeno de estatização da sociedade e de socialização do Estado.

Isso porque volta a ser atribuída ao espaço público e à Administração uma função relevante com relação à sociedade e ao indivíduo.

Todas essas transformações se dão sob a égide da lei, que apenas passa a receber uma conotação política mais destacada, não havendo renúncia ao primado do Estado de Direito, mas apenas uma transformação em razão das demandas surgidas no período.

Logo, com as novas tarefas do Estado, o livre desenvolvimento da personalidade não mais se baseia no apego à propriedade contra a intervenção estatal, excludente de boa parcela da população, mas se funda nas próprias prestações estatais.

O arbítrio dos poderes públicos é evitado mediante a reserva da lei e do princípio democrático, característicos do Estado de Direito.

A busca de melhorias sociais e econômicas dá-se sem o sacrifício das garantias jurídico-formais do Estado de Direito. Afinal, a liberdade é inconcebível sem a solidariedade, e a igualdade e progresso sócio-econômicos devem fundar-se no respeito à legalidade democrática (SILVA, 1993).

Por fim, tem-se na passagem para o Estado democrático de Direito, um acréscimo do ideal participativo e democrático amplo ao aspecto formal, que, como o próprio nome indica, o faz notadamente, por meio do Direito, assim o "constitucionalismo, exsurgente do Estado 
Democrático de Direito, pelo seu perfil compromissário, dirigente e vinculativo, constitui-a-ação do Estado"(STRECK 2001).

Assim, o Estado Liberal, Estado social ou de bem estar social e Estado Democrático nada mais são do que versões pautadas por fins e aspectos materiais e de conteúdo diferenciados, da forma Estado de Direito surgida na Idade Moderna por ocasião da consecução jurídica dos ideais burgueses na ruptura com o absolutismo, consolidadas e institucionalizadas o primeiro.

Desde então, a necessária vinculação de todos os poderes estatais à lei e, mais do que isso à Constituição, constitui característica fundamental sobre a qual se assentam as forma estatais aqui abordadas.

Por isso a constitucionalidade é o pilar da visão contemporânea do Estado Democrático de Direito, consagrando e resguardando os direitos fundamentais, realizando um filtro hermenêutico das normas vigentes, legitimando/deslegitimando o Poder estatal, bem como uma nova função de realização de garantias assumida pelo Poder Judiciário e, ainda, delimitando essa função.

Logo, o Estado Democrático de Direito emerge como parâmetro de racionalidade e instrumento crítico de ação do jurista, comprometido com a realização da substancial democracia, onde não haja espaço para Poder sem regulação, tampouco para atos de Poder incontroláveis.

Deve ficar consignado que o desafio do Estado Democrático de Direito atualmente é evitar que a divergência entre a normatividade de nível constitucional e ausência de efetividade em especial, pela inflação legislativa e consequente ineficácia da tutela dos direitos fundamentais, que se traduzem nas garantias dos cidadãos - torne os princípios constitucionais letra morta frente à inviabilidade dos instrumentos para sua consecução.

Assim o presente tema desenvolvido é importante e contribui para aprimorar uma base para a compreensão das mudanças das dinâmicas estatais ao longo do tempo frente às demandas sociais de cada época e partindo dessa base, aponta novas demandas que desafiarão a identificação de um novo modelo de Estado, mais voltado para a eficiência dos serviços públicos, efetividades de direitos constitucionalmente protegidos, dentre várias outras demandas sociais atuais. 


\section{7 - REFERÊNCIAS BIBLIOGRÁFICAS:}

BARRETTO, Vicente de Paulo (coord.). "Dicionário de filosofia do direito". Rio Grande do Sul: Unisinos, 2006, BARROSO, Luis Roberto. Neoconstitucionalismo e Constitucionalização do Direito (O Triunfo Tardio do Direito Constitucional no Brasil). Rio de Janeiro: Revista da EMERJ, vol. 9, n. ${ }^{\circ}$ 33, 2006.

Neoconstitucionalismo e Constitucionalização do Direito (O Triunfo tardio do Direito Constitucional do Brasil), p. 204. In: SARMENTO, Daniel e NETO, Cláudio Pereira de Souza. A constitucionalização do Direito, fundamentos teóricos e aplicações específicas. Rio de Janeiro. Ed. Lúmen Júris. 2007

BOBBIO, Norberto. A era dos direitos/ Norberto Bobbio; tradução de Carlos Nelson Coutinho; apresentação de Celso Lafer. Nova edição. Rio de Janeiro: Elsevier, 2004

BOBBIO, Norberto. Estado Governo Sociedade. Para uma teoria geral da política, 13. ${ }^{\text {a }}$ ed., tradução Marco Aurélio Nogueira. São Paulo:Paz e Terra, 2007

BONAVIDES, Paulo. Do Estado Liberal ao Estado Social. 6. ${ }^{a}$ ed. São Paulo: Malheiros, 1996

BONAVIDES, Paulo. O direito constitucional e o modelo político. Revista de Informação Legislativa, Brasília, ano 21, p. 221-222, jan./mar., 1984

CAMPILONGO, Celso Fernandes. Direito e democracia. São Paulo: Max Limonad, 1997

CANOTILHO, José Joaquim Gomes. Direito Constitucional, 5. a ed. Coimbra: Almedina, 1991

CARVAlHO, Amilton Bueno de. Direito Alternativo: Teoria e Prática. Porto Alegre: Síntese, 1998, p. 50.

COPETTI, André. A Jurisprudencialização da Constituição no Estado Democrático de Direito. Revista de Estudos Criminais, Rio Grande do Sul, vol. 2, nº. 7, 19-44, 2002.

COSTA, Nelson Nery. Ciência Política. Rio de Janeiro: Forense, 2006

COUTINHO, Jacinto Nelson de Miranda. O papel do novo juiz no processo penal. In: COUTINHO, Jacinto Nelson de Miranda (coord.). Crítica à Teoria Geral do Processo Penal. Rio de Janeiro: Renovar, 2001, p. 46.

DALLARI, Dalmo de Abreu. Elementos de Teoria Geral do Estado. 18. a. ed. São Paulo: Saraiva, 1989

DE LA CUEVA, Mario. La Idea del Estado. 5a . ed. México, D.F.: Fondo de Cultura Econômica, 1996, FERRAJOLI, Luigi. Direito e Razão. Teoria do Garantismo penal, traduzido por Ana Paula Zomer, Fauzi Hassan Choukr, Juarez Tavares e Luiz Flávio Comes. São Paulo: Revista dos Tribunais, 2002. 
FERRAZ JÚNIOR, Tércio Sampaio. Constituição Brasileira: modelo de Estado, Estado Democrático de Direito, objetivos e limites jurídicos. In: MIRANDA, Jorge (org.). Perspectivas Constitucionais nos 20 anos da Constituição de 1976. Coimbra: Coimbra Editora, 1998.

FERREIRA FILHO, Manoel Gonçalves. Estado de Direito e Constituição. 2. a ed. São Paulo: Saraiva, 1999.

FILHO, Luciano Américo Galvão. Noções sobre o princípio da separação das funções. Revista dos Tribunais, São Paulo, ano 84, vol 717, julho de 1995

FIORAVANTI, Maurizio. Los Derechos fundamentales, apuntes de historia de las constituciones. 5. ${ }^{\text {e }}$ ed., Madrid: Editorial Trotta, 2007

GARCIA, Emerson. Principio da Separacão dos Poderes: Os órgãos jurisdicionais e a concreção dos Direitos Sociais. Revista da EMERJ, Rio de Janeiro, vol. 8, n. ${ }^{\circ}$ 30, p. 129 - 167 , 2005.

GOLDSCHMIDT, Werner. Dikelogía - La Ciência de La Justicia. Buenos Aires: Depalma, 1987.

HAYEK, Friedrich von. Os fundamentos da liberdade. Brasília :Universidade de Brasília, 1983.

IBAÑEZ, Perfecto Andrés. Poder Judicial e Democracia Política: Lições de um século. Revista de Estudos Criminais, São Paulo, v.2, n. ${ }^{\circ}$ 6, p. 13-25, 2002.

IBAÑEZ, Perfecto Andrés. Poder Judicial e Democracia Política: Lições de um século. Revista de Estudos Criminais, São Paulo, v.2, n. ${ }^{\circ}$ 6, p. 13-25, 2002.

LAVIÉ, Humberto Quiroga. Derecho Constitucional. Buenos Aires: Depalma, 1987 LOPES JUNIOR., Aury. Introdução crítica ao Processo Penal Fundamentos da Instrumentalidade Garantista. 2. ${ }^{\text {a }}$ ed. Rio de Janeiro: Lumen Juris, 2005.

MACHADO, Mario Brockmann. Separação de poderes e controle externo do judiciário. Caderno de Direito Constitucional e Ciência Política. Instituto Brasileiro de Direito Constitucional. Revista dos Tribunais, São Paulo, ano 3, n. ${ }^{\circ}$ 9, p. 81-86, out./dez. 1994.

MARINHO, Guilherme. Tutela jurisdictional e tutela legal (aspectos antecipatorios). Estudos continuados de teoria do processo. Estudos continuados de teoria do processo. A pesquisa jurídica no curso de mestrado em direito processual - vol. I. In, LEAL, Rosemiro Pereira (Coord.) Porto Alegre: Síntese, 2000.

MIRANDA, Jorge. Manual de Direito Constitucional. v.2, 3. a ed. Coimbra: Coimbra, 1991 NEVES, Marcelo.Entre Têmis e Leviatã: uma relação difícil. São Paulo: Martins Fontes, 2006.

RANGEL, Paulo. O Garantismo Penal e o aditamento à denuncia. Revista da EMERJ, Rio de Janeiro, vol. 4, n. 13, p. 178-208, 2001. 
SAAVEDRA, Modesto. Estado Constitucional y Derecho Alternativo. Revista da AJURIS: Porto Alegre, n. ${ }^{\circ} 71$, nov/1997, p. 355.

SCAFF, Fernando. A responsabilidade do Estado Intervencionista. São Paulo: Saraiva, 1990

SILVA, José Afonso da, Curso de Direito Constitucional Positivo, $9^{\mathrm{a}}$ ed, São Paulo, Malheiros, 1993.

SILVA, Ovidio Araujo Baptista da. Processo e ideologia: o paradigma racionalista. Rio de Janeiro: Forense, 2004.

STRECK, Lênio. Jurisdição Constitucional e Hermenêutica. Porto Alegre, Livraria do advogado, 2001.

Jurisdição Constitucional e Hermenêutica: uma nova crítica do direito. Porto Alegre: Livraria do Advogado, 2002.

; MORAIS, Jose Luiz Bolzan de. Ciência Política e Teoria Geral do Estado. $3^{\mathrm{a}}$. ed. Porto Alegre: Livraria do Advogado, 2003.

VIEIRA, Oscar Vilhena. A violação sistemática dos direitos humanos como limite à consolidação do Estado de Direito no Brasil, 1. a. ed., Coordenação Beatriz di Giorgi, Flávia Piovesan e Celso Fernandes Campilongo, São Paulo: Revista dos Tribunais, 1995.

WUNDERLICH, Alexandre. Por um Sistema de Impugnações no Processo Penal Constitucional Brasileiro. In: Escritos de Direito e Processo Penal em Homenagem ao Professor Paulo Cláudio Tovo. Rio de Janeiro: Lúmen Júris, 2001.

ZOLO, Danilo e Costa, Pietro. O Estado de Direito: história, teoria, crítica. São Paulo: Martins Fontes, 2006

i "A instituição do Estado de Direito, inobstante estar ligada conceitualmente ao pensamento germânico dos séculos XVII e XVIII, tem suas raízes em tempo muito anterior a estes. Num lapso temporal de mais ou menos mil anos, observa-se a construção de uma série de ideias que deságuam na concepção única do Estado de Direito. Assim, temos na filosofia grega as ideias de dike (processo), themis (direito) e nomos (lei), na antiguidade, a ideia de uma constituição mista carregava consigo a pretensão de um poder regulado, moderado, em contraposição à tirania ilimitada; ideia de vinculação do soberano às leis fundamentais do reino; as doutrinas de resistência contra tiranos e do contrato social; e, por fim, o pensamento medieval da liberdade no Direito, ou seja, a liberdade a partir de um determinado estatuto que conduziria à ideia de liberdade natural do homem" COPETTI, André. A Jurisprudencialização da Constituição no Estado Democrático de Direito. Revista de Estudos Criminais, Rio Grande do Sul, vol. 2, n. 7, 19-44, 2002, p.20.

ii “A expressão Estado de Direito, foi cunhada na Alemanha: é o Rechtsstaat. Aparece num livro de Welcker, publicado em 1813, no qual se distinguem três tipos de governo: despotismo, teocracia e Rechtsstaat. Foi igualmente na Alemanha que se desenvolveu, nos planos filosófico e teórico, a doutrina do Estado de Direito. Na pegadas de Kant, Von Mohl e, mais tarde, Stahl lhe deram a feição definitiva". HAYEK, Friedrich von. Os fundamentos da liberdade. Brasília :Universidade de Brasília, 1983, p.239.

iii Ibañez afirma que: "No Estado liberal de Direito não há separação, mas antes identificação ou confusão de ambas as esferas: a lei - que é sempre lei ordinária - não representa um limite à ação de uma maioria no governo, que pode dispor dela na forma que conjunturamente mais lhe convenha" e apresenta os traços caracterizadores de tal Estado "a) integração subordinada ao marco do Executivo; b) governo da justiça a partir de um ministério; c) cooptação política da cúpula judicial; d) organização hierarquizada na carreira e dependência das expectativas de promoção do 
juiz da sua docilidade e aceitação acrítica dos critérios do vértice judicial-político; e) intensa interferência da hierarquia do poder político no poder jurisdicional; f) dependência política do Ministério Publico; g) seleção dos operadores com base num critério-imediato ou mediaticamente-político; h) acentuada formação positivista dos operadores judiciais, que os fez verem-se a si próprios como puros técnicos em Direito, neutrais e assépticos; i) como consequiência necessária, a ausência de independência externa e interna da magistratura e do juiz"- IBAÑEZ, Perfecto Andrés. Poder Judicial e Democracia Política: Lições de um século. Revista de Estudos Criminais, São Paulo, v.2, n. ${ }^{\circ}$, p. 13-25, 2002. p. 15-16.

iv "para a fruição dos direitos dos indivíduos é necessário que o Estado seja estruturado de uma forma especifica voltada a limitar o seu poder. A regra fundamental desse modelo de Estado é a separação de poderes, sendo garantido aos indivíduos a possibilidade de recorrerem a um poder judiciário todas as vezes que se virem ameaçados em seus direitos. Nesse sentido, a idéia de Estado de Direito se torna um elemento essencial ä consolidação, aprofundamento e sobrevivência do regime democrático. A democracia exige essa normalidade, pois fora dela não há como se falar em garantia de direitos. Pressupõe um ambiente estruturado com base numa racionalidade legal, dotado de instituições jurídicas que respondam a uma ética própria do espaço público. Toda vez que esse sistema for colocado em xeque a democracia estará em risco" VIEIRA, Oscar Vilhena. A violação sistemática dos direitos humanos como limite à consolidação do Estado de Direito no Brasil, 1. ․ ed., Coordenação Beatriz di Giorgi, Flávia Piovesan e Celso Fernandes Campilongo, São Paulo: Revista dos Tribunais, 1995, p. 191.

v "A ruptura revolucionária é um acontecimento especificamente francês. O "modelo francês", mesmo que destinado a produzir efeitos de grande alcance para toda a Europa, não é, contudo, a única resposta possível ao problema de relação entre poder e direito (direitos): ao contrário, um grande país Europeu, a Inglaterra, tinha precocemente mostrado como compor a vocação "absoluta" da soberania com um sistema de vínculos capazes de limitar a sua arbitrariedade e proteger os sujeitos a ponto de constituir um marco de referência exemplar para o numerosos intelectuais franceses que, no Século das Luzes, viam prosperar nela aquele espírito de liberdade e de tolerância ainda fortemente hostilizado na sua pátria.” In, ZOLO, op. cit. p, 112.

vi "Por esto es totalmente legitimo afirmar - como ya hemos hecho antes - que el punto débil de la revolución está en la garantia de los derechos. Garantia que lógica, cultural e historicamente está ligada al concepto de rigidez constitucional, es decir, a la presencia de uma constitución que sea como tal capaz de imponerse, para fines de garantia, sobre las voluntades normativas del poder político, incluída la ley, tan exaltada en el curso de la revolución". In, FIORAVANTI, Maurizio. Los Derechos fundamentales, apuntes de historia de las constituciones. 5. ${ }^{a}$ ed., Madrid: Editorial Trotta, 2007, p. 74.

vii "Segundo Locke, o verdadeiro estado do homem não é o Estado civil, mas o natural, ou seja, o estado de natureza no qual são livres e iguais, sendo o estado civil uma criação artificial, que não tem outra meta além da de permitir a mais ampla explicitação da liberdade e da igualdade naturais”. In, BOBBIO, Norberto. A era dos direitos/ Norberto Bobbio; tradução de Carlos Nelson Coutinho; apresentação de Celso Lafer. Nova edição. Rio de Janeiro:

Elsevier, 2004. p, 48.

viii "Locke parte da condição natural dos homens, do estado de natureza, mas via essa condição de um modo diferente de Hobbes. Para ele, o estado de natureza era um estado de liberdade e de igualdade, não a guerra virtual de todos contra todos. Portanto, o estado de natureza era regido por uma lei de natureza que a todos obrigava. A razão, que era essa lei, ensinava a todos os homens que eram iguais e independentes, que nenhum deles devia prejudicar a outrem na vida, na saúde, na liberdade ou na propriedade. Cada um devia, além disso, garantir a execução dessa lei de natureza, punindo de maneira eficaz aqueles que a transgredissem.” COSTA, Nelson Nery. Ciência Política. Rio de Janeiro: Forense, 2006, p. 110.

ix “A inversão do sistema de dominação a partir da Revolução Francesa teve, em verdade, apenas uma remodelagem, uma nova gravação de um longa metragem com mudança de atores, mas mantendo-se o mesmo local de fala. A produção do direito passou a ser exclusividade do Estado com a substituição dos monarcas pelo Poder Legislativo". SILVA, Ovidio Araujo Baptista da. Processo e ideologia: o paradigma racionalista. Rio de Janeiro: Forense, 2004, p. 35.

x "Pode-se, então, dizer que a transformação no viés intervencionista do Estado Moderno Liberal o faz assumir responsabilidades organizativas e diretivas do conjunto da economia do País, em vez de simplesmente exercer poderes gerais de legislação e polícia, próprias do perfil do Estado Mínimo, como era até então conhecido. Em virtude disso, pode-se dizer que o Estado do Bem-Estar Social, constitui uma experiência concreta da total disciplina pública da economia, assumindo como modelo de futuros objetivos autoritários da política econômica e ao mesmo 
tempo cria hábitos e métodos dirigistas dificilmente anuláveis”. STRECK, Lênio Luiz; MORAES, Jose Luiz Bolzan de. op. cit. p. 72.

xi Como afirma Tércio Ferraz Junior ao analisar a Constituição da República: “induz, obviamente, a que se pense, de um lado, nos tradicionais princípios do Estado de Direito (exercício de direitos sociais e individuais, liberdade, segurança, igualdade, etc...), mas de outro, nas exigências das necessidades de democratização da própria sociedade (que há de ser fraterna, pluralista, sem preconceitos, fundada na harmonia social, etc...)”. FERRAZ JÚNIOR, Tércio Sampaio. Constituição Brasileira: modelo de Estado, Estado Democrático de Direito, objetivos e limites jurídicos. In: MIRANDA, Jorge (org.). Perspectivas Constitucionais nos 20 anos da Constituição de 1976. Coimbra: Coimbra Editora, 1998, 3 v., p. 39.

xii "Com o nascimento do Estado Constitucional Democrático de Direito, a teoria crítica jurídica prega a necessidade de uma adequação ao novel paradigma de produção científica. Deve-se criar uma ruptura com direito meramente regulador, para que se possa ingressar no modelo de direito promovedor e transformador. Em síntese, basta referir que os processualistas contemporâneos têm se orientado por uma tutela constitucional do processo, tendo o processo como instrumento a serviço da ordem constitucional”. In, WUNDERLICH, Alexandre. Por um Sistema de Impugnações no Processo Penal Constitucional Brasileiro. In: Escritos de Direito e Processo Penal em Homenagem ao Professor Paulo Cláudio Tovo. Rio de Janeiro: Lúmen Júris, 2001, p. 25.

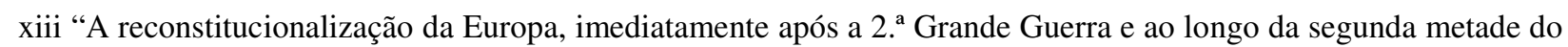
século XX, redefiniu o lugar da Constituição e a influência do direito constitucional sobre as instituições contemporâneas. A aproximação das idéias de constitucionalismo e de democracia produziu uma nova forma de organização política (...) a principal referência no desenvolvimento do no direito constitucional é a Lei Fundamental de Bonn (Constituição Alemã), de 1949, e, especialmente, a criação do Tribunal Constitucional Federal, instalado em 1951. A partir daí, teve início uma fecunda produção teórica e jurisprudencial, responsável pela ascensão científica do direito constitucional no âmbito dos países de tradição romano-germânica. A segunda referência é a da Constituição da Itália, de 1947, e a instalação da Corte Constitucional, em 1956. Ao longo da década de 70, a redemocratização e a reconstitucionalização de Portugal (1976) e Espanha (1978), agregaram valor e volume ao debate sobre o novo direito constitucional. No caso brasileiro, o renascimento do direito constitucional se de igualmente, no ambiente de reconstitucionalização do país, por ocasião da discussão prévia, convocação, elaboração e promulgação da Constituição de 88”. In, BARROSO, Luis Roberto. Neoconstitucionalismo e Constitucionalização do Direito (O Triunfo Tardio do Direito Constitucional no Brasil). Rio de Janeiro: Revista da EMERJ, vol. 9, n..$^{\circ} 33$, 2006, p.45.

xiv A idéia de tal princípio acarreta as seguintes consequiências: "1) o princípio da unidade em que as normas inferiores devem se adequar às normas superiores contidas na Constituição; 2) o princípio do controle da constitucionalidade, isto é, de verificação da compatibilidade das normas inferiores com a Constituição; 3) o princípio da razoabilidade, segundo o qual as normas infraconstitucionais devem ser instrumentos ou meios adequados (razoáveis) aos fins estabelecidos na Constituição; 4) o princípio de rigidez para a reforma da Constituição, que não pode ser feita pelo mesmo procedimento de elaboração da norma legislativa comum; 5) a distinção entre poder constituinte e poder constituído, que é a distribuição de competência funcional a determinar quem pode criar os diversos níveis jurídicos; 6) a gradação do ordenamento jurídico em diversos níveis, desde a norma fundamental abstrata até o ato de execução pelo órgão público; 7) a garantia do Estado de Direito, pois os órgãos públicos se encontram limitados pelas determinações do poder constituinte." In, LAVIÉ, Humberto Quiroga. Derecho Constitucional. Buenos Aires: Depalma, 1987, p. 47.

xv Jorge Miranda afirma que o paradigma constitucional surge e apresenta evoluções "com natureza, significação, características e funções diversas consoante as diferentes correntes doutrinais que atravessam os séculos XIX e

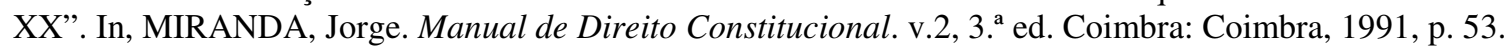

xvi “A democracia é um sistema político-cultural que valoriza o indivíduo frente ao Estado e que se manifesta em todas as esferas da relação Estado-indivíduo. Inegavelmente, leva a uma democratização do processo penal, refletindo essa valorização do indivíduo no fortalecimento do sujeito passivo do processo penal. Pode-se afirmar, com toda segurança, que o princípio que primeiro impera no processo penal é o da proteção dos inocentes (débil), ou seja, o processo penal como direito protetor dos inocentes. Esse status (inocência) adquiriu caráter constitucional e deve ser mantido até que exista uma sentença penal condenatória transitada em julgado". - In, LOPES JUNIOR., Aury. Introdução crítica ao Processo Penal Fundamentos da Instrumentalidade Garantista. 2. a ed. Rio de Janeiro: Lumen Juris, 2005, p. 39.

xvii "as ações concretas atribuídas ao Estado Social traduzem-se na defesa dos direitos do trabalho, da previdência, da educação, intervenção do Estado na economia como distribuidor; o Estado dita o salário, manipula a moeda, 
regula os preços, combate o desemprego, protege os enfermos, dá ao trabalhador e ao burocrata a casa própria, controla as profissões, compra a produção, financia as exportações, concede crédito, institui comissões de abastecimento, provê necessidades individuais, enfrenta crises econômicas, coloca na sociedade todas as classes na mais estreita dependência de seu poderio econômico, político e social.” BONAVIDES, Paulo. Do Estado Liberal ao Estado Social. 6. ${ }^{a}$ ed. São Paulo: Malheiros, 1996, p. 186.

xviii Também, atribuiu-se competência ao judiciário para julgar a inconstitucionalidade das leis. O judiciário do império não tinha essa competência, e, além disso, não conseguia controlar o contencioso administrativo, que retirava de sua apreciação as grandes causas publicas. E o Senado passou a julgar o impeachment dos ministros do Supremo Tribunal por crimes de responsabilidade.

xix No dia 28 de agosto de 1979, vem à lume a lei 6683/79, composto de 15 artigos, diz em seu artigo no 1 "É concedida anistia a todos quanto, no período compreendido entre 2 de setembro de 1961 e 15 de agosto de 1979 , cometeram crimes políticos ou conexos com estes, crimes eleitorais aos que tiveram seus direitos políticos suspensos e aos servidores da administração direta e indireta, de fundações vinculadas ao poder público, aos servidores dos Poderes Legislativo e Judiciário. Aos militares e representantes sindicais punidos com fundamento em atos institucionais e complementares e outros diplomas legais". Composto de 3 parágrafos, diz em seu $2^{\circ}$ parágrafo "Executam-se dos benefícios da anistia os que foram condenados pela prática de crimes de terrorismo, assalto, sequestro e atentado pessoal". Em novembro de 1985, o governo, através de uma Emenda Constitucional ( ${ }^{\circ}$ 26) concede anistia a "todos os servidores públicos da Administração Direta e Indireta e Militares, punidos por atos de exceção, institucionais ou complementares (art. $\left.4^{\circ}\right)$. No $1^{\circ}$ parágrafo diz: "É concedida, igualmente, anistia aos autores de crimes políticos ou conexos, e aos dirigentes e representantes de organizações sindicais e estudantis, bem como aos servidores civis ou empregados que hajam sido demitidos ou dispensados por motivação exclusivamente política, com base em outros diplomas legais". A Constituição de 1988, nos Atos das Disposições Constitucionais Transitórias, determina, no seu artigo $8^{\circ}$ "É concedida anistia aos que, no período de 18 de setembro de 1946 até a data da promulgação da Constituição, foram atingidos em decorrência de motivação exclusivamente política, por atos de exceção, institucionais ou complementares, aos que foram abrangidos pelo Decreto Legislativo $\mathrm{n}^{\circ} 18$ de 15/12/1961, e aos atingidos pelo Decreto-Lei n ${ }^{\circ} 864$ de 12/09/1969, asseguradas as promoções, na inatividade, ao cargo, emprego, posto ou graduação a que teriam direito se estivessem em serviço ativo, obedecidos os prazos de permanência em atividades previstas nas leis, regulamentos vigentes, respeitadas as características e peculiaridades das carreiras dos servidores públicos civis e militares e observados os respectivos regimes jurídicos".

xx A eleição indireta para Governador, que vinha desde 1965, desapareceu com a EC-15, de 1980, voltando a ser direta, por voto secreto e sufrágio universal, para mandato quadrienal. Em 1982, foi aplicada em sua plenitude a tese do voto vinculado para todas as eleições, exceto a do Presidente e Vice-Presidente da República.

xxi Trata-se da lei 5250/67 que com o advento da Constituição da República de 1988, várias modificações sofreu. A principal delas foi quando à legitimação das liberdades de expressão, informação e de imprensa, que se encontra no Título VII, Capítulo V, Da Comunicação Social, artigos 220 a 224 da Constituição da República de 1988. Este capítulo inscreveu normas de comunicação coletiva, extinguiu a censura, inseriu o direito de resposta, o dever de informar e o direito de ser informado.

xxii Como expõe Marcelo Neves: “(...) aqueles que pertencem às camadas sociais "marginalizadas” são integrados ao sistema jurídico, em regra, como devedores, indiciados, denunciados, réus, condenados etc..., não como detentores de direitos, credores ou autores". NEVES, op. cit. p. 249.

471 